\title{
Uma política pública e participativa para as línguas brasileiras: sobre a regulamentação e a implementação do Inventário Nacional \\ da Diversidade Linguística (INDL)
}

Rosângela Morello (IPOL)

\section{Resumo}

Este texto aborda a primeira política linguística brasileira pública de abrangência nacional, instituída pelo Decreto federal no. 7.387, de 09 de dezembro de 2010: o Inventário Nacional da Diversidade Linguística Brasileira (INDL). Trazendo um histórico dos trabalhos que precederam ao Decreto, discutiremos na sequência, algumas prerrogativas para sua regulamentação e implementação, em especial, a que prevê a participação das comunidades linguísticas no processo.

Palavras-chave: linguas brasileiras; inventário; diversidade linguística; política linguística; gestão de linguas. 


\section{A política linguística do Inventário Nacional da Diversi- dade Linguística (INDL) - alguns precedentes}

Antes de iniciarmos a discussão propriamente prevista para este texto, merece destaque o fato de, neste momento, ser necessário qualificar uma política linguística no Brasil. Nada mais salutar em nossa história! Após um longo período de silenciamento e de interdição de línguas em prol de um Estado Nacional alicerçado sobre a língua Portuguesa como única língua oficialmente reconhecida e promovida, chegamos a um momento de afirmação e promoção da diversidade linguística, com políticas de reconhecimento das línguas brasileiras e de fortalecimento de sua presença em variados âmbitos sociais. A oficialização nacional da língua brasileira de sinais (LIBRAS), a cooficialização de línguas por municípios ${ }^{1}$, a implementação de programas de educação escolar bilíngues e a oferta de cursos universitários contemplando formação em linguas indígenas, de sinais e de imigração são alguns exemplos desse novo modo de entendimento das línguas no Brasil. Justamente dessa vivacidade emerge a demanda, muito positiva, de um planejamento qualificado das ações visando a fortalecer as distintas comunidades linguísticas. Neste quadro inserimos nossas considerações sobre o INDL no intuito de contribuir para o debate sobre sua gestão.

Ao menos dois trajetos se entrecruzam na história do decreto federal 7.387/2010 que criou o Inventário Nacional da Diversidade Linguística Brasileira (doravante INDL).

Em um deles estão os movimentos mundiais em defesa das minorias que vicejaram a partir do final da década de 1940 e cujo marco é a Declaração Universal dos Direitos Humanos (1948). Ao longo de mais de seis décadas, tais movimentos geraram acordos e declarações fundamentais para que se estabelecessem direitos culturais e linguísticos na modernidade. Entre os mais importantes documentos encontraremos, em ordem cronológica : a Declaração Universal dos Direitos Humanos (1948); o Pacto Internacional dos Direitos Civis e Políticos e o Pacto Internacional dos Direitos Econômicos, Sociais e Culturais (1966); a Declaração sobre os Direitos de pessoas pertencentes a Minorias Nacionais ou Étnicas, Religiosas e Linguísticas (1992); a Carta Europeia sobre as Línguas Regionais ou Minoritárias (1992); a Declaração da Cúpula do Conselho da Europa sobre as Minorias Nacionais (1993); a Convenção-Marco para a Proteção das Minorias Nacionais (1994); e a Declaração Universal para a Promoção da Diversidade Cultural - Unesco (2005).

${ }^{1}$ Sobre o atual quadro de linguas cooficiais no Brasil - são 9 linguas em 12 municípios - ver Política de Cooficialização de Línguas no Brasil (MORELLO, 2012).
Em 1996, em Barcelona, vem a público a Declaração Universal dos Direitos Linguísticos. Apoiada no conjunto de documentos que a precedem e enquadrando os direitos linguísticos no âmbito dos direitos humanos, em especial no que a Declaração de 1948, em seu artigo segundo, a todos assegura "todos os direitos e 
2 O IPOL Instituto de Investigação e Desenvolvimento em Política Linguística atua no campo das politicas linguísticas e dos direitos linguísticos desde 1999, tendo, ao longo desses anos, proposto e executado censos e diagnósticos linguísticos no Brasil e demais países do Mercosul e assessorado progamas de educação bi ou plutilingues. Participou das ações que originaram a primeira proposta de cooficialização das línguas indígenas no Brasil, em São Gabriel da Cachoeira, Amazonas, da cooficialização do Pomerano em Santa Maria de Jetibá, Espírito Santo e do Hunsrükisch, em Antônio Carlos, Santa Catarina. Teve importante papel gestor nas ações que culminaram no Decreto n. 7.387, sendo responsável pela execução do projeto piloto Inventário da Língua Indígena Guarani Mbya. Este texto resulta, de fato, de todo o trabalho em equipe feito no IPOL, da qual faço parte desde 2004, e a qual muito agradeço.

3 Confere documento disponível em www. ipol.org.br. liberdades" sem distinção de "raça, cor, sexo, língua, religião, opinião política, origem nacional ou social, posição socioeconômica, nascimento ou qualquer outra condição" (2003, p. 8), a Declaração dos Direitos Linguísticos afirma ter surgido "das comunidades linguísticas e não dos Estados [...] e tem como finalidade propiciar a organização de um marco político da diversidade linguística baseado na convivência, no respeito e no benefício recíprocos" (idem, p. 23). Entre as formulações consolidadas por esta Declaração, uma delas pode ser considerada fundadora desse marco político: a que diz respeito à compreensão de comunidade linguística. Retomaremos mais adiante esta formulação para reafirmar as aberturas que oferece a uma gestão democrática e participativa das línguas no Brasil.

Em outro trajeto encontraremos o conjunto dos esforços e iniciativas de comunidades linguísticas brasileiras para se fazer ouvir pelo Estado naquilo que lhes foi historicamente negado pela tradição monolinguista: o reconhecimento de suas línguas como um bem social, fundamental para a plena formulação de seus conhecimentos e expansão de suas formas de vida e trabalho.

A Constituição da Repúlblica Federativa do Brasil de 1988, que reconheceu aos indígenas o direito à língua, cultura e educação próprios e assim definiu um importante marco jurídico em prol dessas comunidades, silenciou, no entanto, sobre todas as demais línguas brasileiras faladas por imigrantes, negros, surdos, ou fronteiriços. Somente mais de uma década mais tarde, a questão das línguas voltará ao debate político.

Em 2002, assistiremos a primeira política de cooficialização de línguas indígenas em nível municipal, em São Gabriel da Cachoeira, Amazonas. Com ela, abria-se precedente para outras iniciativas, fazendo com que chegássemos a 2012 com 9 línguas cooficiais em 12 municípios, sendo 5 indígenas e 4 de imigração.

Em 2004, teremos importante ação institucional em prol do reconhecimento das línguas brasileiras em nível nacional, por meio de uma petição encaminhada pelo $\mathrm{IPOL}^{2}$ à Comissão de Educação e Cultura do Congresso Nacional e que desembocaria no decreto 7.387/2010. O referido documento solicitava a abertura de um Livro de Registro para as Línguas Brasileiras como bem imaterial, ao modo do que o Ministério da Cultura já realizava com bens imateriais como os saberes, as celebrações, as formas de expressão e os lugares ${ }^{3}$. O pedido foi encaminhado ao Instituto do Patrimônio Histórico e Artístico Nacional (IPHAN) pelo então presidente da Comissão de Educação e Cultura, deputado Carlos Abicalil. Após os trâmites interinstitucionais, realizou-se em Brasília, em março de 2006, um seminário legislativo para a discussão sobre a relevância social dessa política. Este seminário contemplou depoimentos de falantes de outras línguas que não o português e ao final, instalou um grupo interinstitucional e interministerial - o Grupo de Trabalho da Diversidade Linguística 
do Brasil (doravante GTDL) - para dar continuidade aos trabalhos, definindo critérios e procedimentos para o registro das línguas brasileiras.

Vale ressaltar que o pedido de abertura de um livro de registro específico para as línguas deu voz a muitas comunidades linguísticas invisibilizadas na história de constituição da nação brasileira e, ao mesmo tempo, trouxe especificidade a demandas já efetivadas ao IPHAN, como a dos falantes do talian solicitando reconhecimento do patrimônio cultural ligado a essa sua língua. De acordo com o relatório do GTDL (2007), de fato o reconhecimento de línguas como patrimônio havia se constituído em uma preocupação da comissão e do grupo de trabalho criados em 1998 pelo Ministério da Cultura para estabelecer as políticas do patrimônio imaterial. No entanto, dúvidas relacionadas a aspectos conceituais e técnicos sobre o registro e o reconhecimento de línguas levaram a um adiamento da decisão. Deixou-se, por isso, em aberto, a possibilidade de criação de novos livros. É este campo de diálogo que é reativado em 2004 e 2006.

Com base na origem histórica e cultural e na natureza semiótica das línguas, o GTDL estabeleceu categorias histórico-sociológicas para as línguas brasileiras, propondo que cada uma fundamentasse ações necessárias ao inventário: i) indígenas; ii) imigração; iii) comunidades afro-brasileiras; iv) sinais; v) crioulas e; vi) língua portuguesa e suas variações dialetais (Relatório de atividades do Grupo de Trabalho da Diversidade Linguística do Brasil, 2007). Propôs ainda que no grupo das línguas indígenas se distinguissem as ações necessárias a duas situações: a das línguas ameaçadas e próximas à extinção e a das línguas de grande população e extensão territorial.

Acionadas pelo GTDL como base para a implementação da política do INDL, estas categorias de línguas foram indicadas como âncoras para ajustes metodológicos e administrativo-financeiros, os quais seriam estabelecidos a partir de projetos pilotos. Um requisito geral foi estabelecido para que qualquer língua tomasse parte do inventário: "ter relevância para a memória e identidade dos grupos que compõem a sociedade brasileira, ser veículo de transmissão cultural e falada no território nacional há pelo menos três gerações (ou 75 anos)" (2007, pag. 11). Em suas considerações sobre a implementação da política de Inventário, diz o GTDL (2007, p. 14):

O Inventário permitirá ao Estado e à sociedade em geral o conhecimento e a divulgação da diversidade linguística do país e seu reconhecimento como patrimônio cultural. Esse reconhecimento e a nomeação das línguas inventariadas como referências culturais brasileiras constituirão atos de efeitos positivos para a formulação e implantação de políticas públicas, para a valorização da diversidade linguística, para o aprendizado dessas línguas pelas novas gerações e para o desenvolvimento do seu uso em novos contextos. 
Além de especificações sobre as línguas a serem inventariadas, o relatório do GTDL trouxe ainda uma refinada análise das condições para a regulamentação e a implementação do INDL, entre as quais está o Decreto publicado em 2010. São aspectos dessas condições que abordaremos a seguir, articulando-os a uma breve discussão sobre a constituição de sentidos para comunidade linguística no Brasil e sua repercussão no âmbito da representação política.

\section{Inventário: documentação, registro e gestão de línguas com participação social}

Defendendo a política do Inventário como "etapa indispensável para o conhecimento e a disseminação de dados sobre a diversidade linguística brasileira e também como um instrumento de reconhecimento e salvaguarda das línguas como patrimônio cultural" (2007: 10), o GTDL indicou os passos para sua regulamentação e implementação. O Decreto 7.387, como dissemos, é parte das recomendações. Além dele, foi indicada a criação de uma Comissão Técnica para ser responsável pela organização institucional, gestão e financiamento do programa. Nas discussões sobre a criação do Livro de Registro das Línguas, de acordo com o relatório, buscou-se um entendimento sobre a atribuição do caráter de brasileiras a todas as línguas faladas no Brasil, mas este não foi consensuado, fazendo com que a abertura do livro fosse postergada. Considerou-se, ainda, que a abertura do Livro seria uma consequência da implantação da política do inventário, inclusive porque dele poderia derivar os critérios para se consolidar o caráter seletivo do Registro como política de salvaguarda destinada, em especial, às línguas em risco de extinção.

Por outro lado, o GTDL encaminhou ainda duas propostas: a de criação de um Sistema de Documentação e Informação com os dados sistematizados pelo INDL e outros já existentes e a de que a política do INDL fosse integrada, constituindo um compromisso no âmbito governamental, e que sua execução contasse com a participação das comunidades linguísticas e fosse compartilhada com a sociedade (2007, p. 14 e 15). A essas ações, o GTDL articulou a necessidade de um escopo e uma metodologia de modo a garantir qualidade e comparabilidade das informações diante da diversidade das situações a serem descritas. Ao estar relacionada com distintas situações históricas das línguas e suas especificidades semiológicas, a metodologia adquire, ela também, ao longo do texto do relatório, qualificações que escapam a uma composição homogênea de critérios universalmente válidos. Dessa compreensão derivou sua implementação em projetos piloto realizados entre 
2008 e 2010, com o objetivo de torná-la funcional e representativa de cada uma das seis categorias de línguas propostas.

Em seu conjunto, as ações recomendadas pelo GTDL, aqui apresentadas de forma sintética, constituem importantes parâmetros para o estabelecimento da política do INDL. Ao Decreto 7.387, de 2010, segue-se agora o desafio muito específico de avançar na sua regulamentação e implementação.

O empenho do IPHAN, no momento atual, para institucionalizar um regulamento interno visando garantir um domínio técnico e administrativo para essa política evidencia sua continuidade e relevância. Uma apurada discussão sobre a especificidade metodológica do trabalho de inventariar linguas bem como das possibilidades de se contemplar suas variadas formas e situações históricas tem tido igualmente lugar. Entra em cena, neste caso, a necessidade de se garantir o foco político do inventário: o de ser instrumento de conhecimento e gestão da realidade linguística brasileira e não apenas de arquivamento de línguas.

Seguindo a linha de ações propostas pelo GTDL, e considerando as inciativas já em andamento, verificamos que a consolidação da política do INDL como política pública de gestão das línguas pelo Estado brasileiro passa por uma apropriação social de seus sentidos e procedimentos, uma vez que em variados pontos do processo de discussão repercutido no relatório, reivindica-se que haja uma participação das comunidades linguísticas e da sociedade em geral. No entanto, igualmente se reconhece o desconhecimento que reina no país sobre a situação das línguas e suas distintas demandas. Esse desconhecimento é especialmente marcante em relação a línguas de base oral, de comunidades rurais ou alijadas de centros urbanos, como é o caso de muitas comunidades falantes de línguas de imigração, de origem afro ou crioulas, sem falar nas variedades do português profundo, estigmatizadas por todo tipo de marca que as distingam do almejado padrão.

\section{Comunidades linguísticas: a busca por reconhecimento e representação}

A questão que então se coloca é que a história de silenciamento e interdição que submeteu inúmeros brasileiros a uma situação de marginalidade linguística (e também identitária), com profundos efeitos sociais ligados à negação de suas línguas (pelos próprios falantes e por seus outros), afeta fortemente sua capacidade de se fazer representar nos âmbitos nacionais institucionalizados de gestão das políticas que lhes dizem respeito. Desse modo, a demanda por participação das comunidades linguísticas formulada pelo GTDL enfrenta o desafio de não se ter ainda, no Brasil, essa representatividade fortemente instalada, exceto, talvez, para as línguas indígenas e de sinais, com estatutos jurídicos definidos e com presença reconhecida em instituições de pesquisa. 
A contradição que se instala nesse espaço da representatividade advinda das condições históricas que determinaram diferentes formas de participação política para as diferentes parcelas da sociedade brasileira tem se constituído, de fato, em um motor dos movimentos sociais no Brasil. A proposição de Fóruns Permanentes para alavancar propostas para políticas públicas, como o que acaba de ser criado para as línguas de imigração, a flexibilização nos assentos de comissões e colegiados instituídos pelo Governo para acolher representantes da sociedade civil e suas instituições, a abertura cada vez mais bem estruturada, de iniciativas que fomentam a participação de amplos setores sociais na formulação de soluções para questões de ordem cultural, técnica/tecnológica ou econômica são alguns dos mecanismos que marcam o enfrentamento de tal contradição.

Se esta contradição perpassa todas as frentes políticas, no campo da gestão das línguas, seu enfrentamento requer ações que possam promover, primordialmente, uma ressignificação do tecido simbólico sobre o qual se instala a própria ideia de identidade e comunidade linguística.

O ideário nacional constitutivo do Estado brasileiro estabeleceu uma identidade comum a todos os brasileiros, tendo por suporte a língua portuguesa. Ser cidadão brasileiro e ser falante da língua portuguesa foram fatos que ideologicamente coincidiram até recente data. Ressaltemos que somente com a constituição de 1998 a cidadania brasileira foi reconhecida a indígenas brasileiros. Essa extraordinária reversibilidade entre identidade brasileira/ língua portuguesa, corolário do monolinguismo, desqualificou imaginariamente todas as demais possibilidades de representação identitária ancorada em outras línguas, no Brasil. Mais do que isso, qualquer indício de composição mais ou menos organizada de agrupamentos linguisticamente coesos passou a ser interpretado como fator de ameaça ao estado nacional ou como distúrbio ao pleno desenvolvimento social dos grupos ${ }^{4}$. Falar uma outra língua ou a língua de sua comunidade se revestiu de valores negativos para os falantes. Fonte de muitos tipos de exclusão, essa carga simbólica se transvestiu historicamente em conceitos ou preconceitos sobre o desempenho linguístico de cada um. E cada um passou a sentir-se responsável pela língua diferente que fala e

4 Na história do Brasil colônia e depois, como Estado independente, teremos leis que proibirão os usos de línguas que não a portuguesa, com penas que iam de torturas e prisões e mortes, passando pelo extermínio sumário de grupos inteiros. Há farta bibliografia sobre esse assunto. pela decisão de transferi-la aos seus, juntamente com os sentidos de ser dela um falante, no Brasil.

Essa condição histórica e ideológica se repercute nos dias de hoje sob a forma de desafios. Para as comunidades linguísticas, de modo geral, e para as falantes de línguas de imigração, afro-brasileiras ou crioulos, de modo particular, porque carecem de qualquer instrumento de reconhecimento em nível nacional, coloca-se a necessidade de criarem canais para agirem e se representarem frente aos poderes constituídos. Os processos de cooficialização de línguas por municípios possuem esse caráter. Em nível nacio- 
nal, o próprio INDL faz demandas por participação de todas as comunidades, em todas as suas faces, cabendo a elas exigir uma forma e um espaço de representação plena nesse processo.

Para o Estado, coloca-se o desafio de mobilizar os agentes políticos e as aparelhagens administrativas para dar voz às comunidades linguísticas. As inciativas, nesse sentido, são de natureza ao mesmo tempo ideológica e técnico-administrativa, uma vez que incidem sobre uma compreensão muito peculiar do próprio sentido de inventário e de patrimônio, e implica em uma posição nova para o Estado: a de institucionalizar uma política pública brasileira de gestão de línguas. Esta política implica uma formulação clara de uma base de dados sobre as línguas, com diretrizes e critérios de acessibilidade voltados ao fomento de políticas linguísticas, possibilitando que elas sejam articuladas entre si e planejadas a médio e longo prazo. Implica igualmente o fomento de espaços abertos ao debate com as comunidades sobre suas demandas no campo das políticas linguísticas.

A Declaração Universal dos Direitos Linguísticos (2003) oferece importantes parâmetros para esse novo entendimento sobre as comunidades linguísticas e seus papéis nos dias de hoje. Na definição proposta nesta Declaração, a concepção de comunidade linguística sugere uma territorialidade geográfica e simbólica para a língua, uma vez que engloba seu espaço de uso e circulação e a autoidentificação do falante com ela. De acordo com a Declaração:

\section{Título Preliminar \\ Conceitos \\ Artigo I}

Esta Declaração entende por comunidade linguística toda a sociedade humana que, assentada historicamente em um espaço territorial determinado, reconhecido ou não, se autoidentifica como povo e desenvolve uma língua comum como meio de comunicação natural e coesão cultural entre seus membros. A denominação língua própria de um território faz referência ao idioma da comunidade historicamente estabelecida neste espaço (p. 23 e 24).

Título Primeiro

Princípios gerais

Artigo 8

Todas as comunidades linguísticas têm direito a organizar e gerir os recursos próprios, com a finalidade de assegurar o uso de sua língua em todas as funções sociais (p. 28).

Todas as comunidades lingüísticas têm direito a dispor dos meios necessários para assegurar a transmissão e a continuidade de futuro de sua lingua (p. 28).

Ao reunir, pela identidade linguística, grupos e pessoas dispersos pelo território, essa concepção de comunidade linguística 
propicia a constituição ou o fortalecimento de vínculos do falante com uma memória e uma história, independentemente de onde ele esteja ou de ser ele falante da língua a que se filia.

Desta perspectiva, a política do inventário pode abordar uma língua e seus usos de modo amplo, englobando o autoreconhecimento do falante como parte dela, validado por seus pares. Com essa ação, o INDL permite que se reafirmem vínculos identitários, alavanca importantíssima para produzir e disponibilizar novos sentidos, agora positivos, para o fato de se falar outra língua ou pertencer a uma distinta comunidade linguística no Brasil.

A presença de mais de 200 línguas no Brasil de hoje - sejam elas indígenas, de imigração, crioulas, afro-brasileiras ou de sinais - embora em número infinitamente menor do que as cerca de 1.500 existente há quinhentos anos ${ }^{5}$, são a expressão de uma diversidade linguística que resistiu e que agora está disponível para que o cidadão brasileiro possa com ela se identificar e nela investir simbolicamente, culturalmente, economicamente.

O INDL, articulado, é claro, a outras ações como a da cooficialização de línguas, pode, assim, iluminar a configuração de um novo quadro para a promoção das línguas brasileiras, agindo na direção da consolidação social e política dessa noção linguas brasileiras como espaço de negociação e de fortalecimento das diversas comunidades linguísticas.

\section{Considerações para fechar este texto e manter o debate}

Ao colocar em discussão as diretrizes de um programa que conduzisse ao reconhecimento e registro das línguas como patrimônio imaterial MORELLO e OLIVEIRA (2006), afirmaram sua relevância como "um espaço de atuação política do Estado Brasileiro, em conjunto com as sociedades civis", e defenderam a criação do livro de registro das línguas como um instrumento que contemplaria ao menos, três linhas de atuação política: a promoção do direito às línguas; a instalação de políticas de registro e circulação das línguas e; a elaboração de equipamentos - instrumentos e dispositivos - articulados às políticas linguísticas.

Estas três linhas de atuação reverberam, de fato, nas questões que aqui colocamos. Passados seis anos, constatamos que se o Decreto 7.387 representa enorme vitória da sociedade brasileira na garantia dos direitos linguísticos para suas mais de 220 comunidades, ele também trouxe para a agenda política e administrativa a necessidade de uma ordenação que permita a gestão das línguas por aqueles que as falam, cuidando para não se reproduzir antigas práticas que excluem da aparelhagem do Estado, das instâncias gestoras e deliberativas, aqueles que historicamente estiveram alijados delas. Concebido como um programa que pudesse ser 
social como um ganho político sem precedentes na história das línguas no Brasil. E nisso está sua maior qualidade e seu maior desafio.

\begin{abstract}
This paper addresses the first Brazilian public language policy nationwide, established by federal decree 7387, issued on December 09, 2010: the Inventory of Brazilian Linguistic Diversity (INDL). First, it is presented a history of works that preceded the decree. Some prerogatives for its regulation and implementation will then be discussed, in particular, providing for the participation of language communities in the process.
\end{abstract}

Keywords: Brazilian languages; inventory; linguistic diversity; language policy; language management.

\title{
REFERÊNCIAS
}

BALDI, César Augusto. Justiça federal: racismo, terras e direitos humanos. Workshop no seminário "repensando o acesso à justiça no brasil", Observatório da Justiça Brasileira, Belo Horizonte, 29 nov. a 4 dez. 2010. Disponível em:

http://democraciaejustica.org/cienciapolitica3/sites/default/files/ justicafederalracismoterrasedireitoshumanoscesarbaldi 2010.pdf. Acesso em: 16 jun. 2010.

BRASIL. Decreto 7.387, de 09 de dezembro de 2010. Disponível em www.planalto.gov.br/ccivi103/_Ato2007.../Decreto/D7387.htm. Acesso em: 15 mai. 2012.

MORELLO, Rosângela. A política de cooficialização de línguas no Brasil. Revista Internacional do Instituto da Lingua Portuguesa, no. 1, 2011 (no prelo).

. SEIFFERT, Ana Paula (orgs.). Inventário da Lingua Guarani Mbya. Florianópolis: IPOL; Editora Garapuvu, 2011.

MORELLO, Rosângela; OLIVEIRA, Gilvan Müller de. Uma política patrimonial e de registro para as línguas brasileiras. Patrimônio - Revista eletrônica do IPHAN, Campinas, n. 6, jan./fev. 2007. Disponível em: http://www.labjor.unicamp.br/patrimonio/materia. php?id=211. Acesso em: 16 jun. 2010.

OLIVEIRA, Gilvan Müller de. O lugar das línguas: a América do Sul e os mercados linguísticos na Nova Economia. Synergies, Brésil, n. esp. 1, p. 21-30, 2010.

. Índios urbanos, línguas urbanas: considerações político-linguísticas sobre a urbanização dos povos indígenas. In: 
Geografia - Revista da Universidade Federal do Amazonhas, v. 3, n. 1/2, p. 07-34, 2004.

. (org.). Declaração Universal dos Direitos Lingüísticos. Campinas, SP. IPOL, Mercado das Letras e ALB, 2003.

. Relatório do Grupo de Trabalho da Diversidade Linguística no Brasil/GTDL. Câmara dos Deputados, Brasília/DF, 2007. RODRIGUES, Aryon D’aligna. Linguas brasileiras : para o conhecimento das linguas indígenas. São Paulo, SP, Edições Loyola, 1986.

SILVA, Fábio Lopes da; MOURA, Heronides Maurílio de Melo (org.). O direito à Fala: a questão do patrimônio lingüístico. Florianópolis, Insular, 2002.

SILVA, Paulo Thadeu Gomes da. Direito linguístico: a propósito de uma decisão judicial. In: Revista internacional de direito e cidadania, n. 9, p. 183-187, fev. 2011.

SOARES, Inês Virgínia Prado. Cidadania cultural e direito à diversidade lingüística: a concepção constitucional das línguas e falares do Brasil como bem cultural. In: Revista internacional de direito e cidadania, n. 1, p. 83-101, jun. 2008. 